\title{
Efficacy and safety of fast-acting insulin aspart versus insulin aspart in children and adolescents with type 1 diabetes from Japan
}

\author{
Tomoyuki Kawamura ${ }^{1)}$, Toru Kikuchi' ${ }^{2}$, Hiroshi Horio ${ }^{3)}$, Naveen Rathor ${ }^{4)}$ and Magnus Ekelund ${ }^{4)}$ \\ 1) Pediatrics Department, Osaka City University Graduate School of Medicine, Abeno Ward, Osaka 558-8585, Japan \\ 2) Department of Pediatrics, Saitama Medical University, Iruma District, Saitama 350-0495, Japan \\ 3) Novo Nordisk Pharma Ltd., Chiyoda Ward, Tokyo 100-1005, Japan \\ 4) Medical \& Science, Global Development, Novo Nordisk A/S, 2860 Søborg, Denmark
}

\begin{abstract}
The aim of this post-hoc subgroup analysis, which was based on data from the treat-to-target, 26-week, onset 7 trial, was to confirm the efficacy and safety of fast-acting insulin aspart (faster aspart) versus insulin aspart (IAsp), both in combination with basal insulin degludec, in children and adolescents from Japan with type 1 diabetes (T1D). Of the onset 7 trial population ( 1 to $<18$ years; $N=777$ ), 66 participants from Japan (65 Asian and one non-Asian) were randomized to mealtime faster aspart $(n=24)$, post-meal faster aspart $(n=19)$, or IAsp $(n=23)$. Data for the subgroup from Japan were analysed descriptively. Change from baseline in hemoglobin A1c 26 weeks after randomization was $0.23 \%, 0.74 \%$, and $0.39 \%$, for mealtime faster aspart, post-meal faster aspart, and IAsp respectively. Change from baseline in 1-h post-prandial glucose increment (based on 8-point self-measured blood glucose profiles) showed numerical differences in favor of mealtime faster aspart versus IAsp at breakfast $(-30.70 v s .-2.88 \mathrm{mg} / \mathrm{dL})$ and over all meals $(-18.21 v s .-5.55 \mathrm{mg} / \mathrm{dL})$. There were no clinically relevant numerical differences between treatment arms in the overall rate of severe or blood glucose-confirmed hypoglycemia. At week 26, mean total insulin dose was $1.119 \mathrm{U} / \mathrm{kg} /$ day for mealtime faster aspart, $1.049 \mathrm{U} / \mathrm{kg} / \mathrm{day}$ for postmeal faster aspart, and $1.037 \mathrm{U} / \mathrm{kg} /$ day for IAsp. In conclusion, in children and adolescents with T1D from Japan, mealtime and post-meal faster aspart with insulin degludec was efficacious in controlling glycemia without additional safety concerns versus IAsp.
\end{abstract}

Key words: Type 1 diabetes, Fast-acting insulin aspart, Children, Adolescents, Japan

IN JAPAN, the incidence of type 1 diabetes (T1D) under 15 years of age is 2.25 cases per 100,000 persons per year [1]. This is low compared with other countries, with Caucasian and some Middle Eastern populations having incidences of 20 and 41/100,000 persons per year, respectively [2]. T1D pathogenesis may be different between Japanese and Caucasian populations. Several genes have been associated with T1D susceptibility in both Japanese and Caucasian populations, but there are slight differences in specific disease-causing alleles between these populations [3].

Current guidelines on the management of T1D in children and adolescents stress the importance of immediately starting intensive insulin therapy following

Submitted Mar. 24, 2020; Accepted Oct. 29, 2020 as EJ20-0116 Released online in J-STAGE as advance publication Jan. 29, 2021 Correspondence to: Tomoyuki Kawamura, Pediatrics Department, Osaka City University Graduate School of Medicine, Abeno Ward, Osaka 558-8585, Japan.

E-mail:kawam@med.osaka-cu.ac.jp diagnosis [4-6]. Intensive insulin treatment is based on basal-bolus dosing, using a combination of long-acting insulin to cover the basal insulin need and bolus doses with rapid-acting insulin to attenuate meal-based glucose changes, or on continuous subcutaneous insulin infusion of rapid-acting insulin administered with an insulin pump [4, 5, 7]. The International Society for Pediatric and Adolescent Diabetes (ISPAD) recommends that glycemic control should be measured in children with T1D every 3 months, with a target of hemoglobin A1c $<7.0 \%$ for children, adolescents, and young adults who have access to comprehensive care [8]. The Japan Diabetes Society also recommends a target of hemoglobin A1c $<7.0 \%$ [9].

There are a number of challenges to achieving good glycemic control without significant hypoglycemia with insulin therapy in children and adolescents with T1D [4, $5,10]$. Reasons for this are multifactorial and include avoidance or overcorrection of hypoglycemia, physiologic insulin resistance, increasing weight, height and 
caloric needs, and unpredictable dietary intake and meal patterns $[7,10]$. Controlling post-prandial glucose (PPG) excursions is a key component in achieving recommended hemoglobin A1c, particularly in Asian versus Caucasian patients $[11,12]$. In Japanese patients with insulin-treated diabetes, there was a significant positive correlation between PPG levels after each meal (breakfast, lunch or dinner) and hemoglobin Alc level [12]. However, post-prandial hyperglycemia is difficult to manage, especially in children, and there is an unmet need for exogenous mealtime insulin analogues that better mimic physiology $[7,10,13]$.

Fast-acting insulin aspart (faster aspart) is an ultrarapid acting formulation of insulin aspart (IAsp) with two added excipients- $-\mathrm{L}$-arginine and niacinamide - to optimize stability and accelerate absorption after subcutaneous administration [14]. In Japanese patients with T1D, the onset of appearance of faster aspart was two times more rapid than IAsp (3.0 vs. 7.1 minutes, respectively; $p<0.001$ ), with onset of action 5 minutes earlier (20.2 vs. 25.5 minutes, respectively; $p=0.001$ ); and greater early glucose-lowering effect [15]. These results confirm that the pharmacology of faster aspart in Japanese patients is similar to that observed in European children, adolescents, and adults $[16,17]$.

The onset 7 trial in children and adolescents with T1D reported that mealtime and post-meal faster aspart were non-inferior to IAsp in terms of change from baseline in hemoglobin Alc (estimated treatment difference [95\% CI] mealtime $-0.17 \%[-0.30 ;-0.03]$, post-meal $0.13 \%$ $[-0.01 ; 0.26])$, with superiority confirmed for mealtime faster aspart versus IAsp [18]. The aim of this post-hoc subgroup analysis of onset 7 was to assess the efficacy and safety of faster aspart versus IAsp, both in combination with basal insulin degludec, in children and adolescents with T1D in Japan. The experiences of faster aspart in a Japanese population, particularly in terms of safety outcomes, is of value for Japanese pediatricians who are responsible for patients with T1D.

\section{Methods}

\section{Trial design}

The methodology and results of the onset 7 trial (NCT0267091) have been previously reported [18]. In brief, onset 7 was a phase 3, 26-week, multicenter (150 sites across 17 countries), randomized, double-blind, parallel-group trial. The trial compared the efficacy and safety of mealtime faster aspart with that of mealtime IAsp, both in combination with insulin degludec, in children and adolescents with T1D [18]. In an additional open-label treatment arm, participants received postmeal faster aspart, also in combination with insulin degludec [18]. Randomization was stratified by age using the following age groups: $\geq 1-<3, \geq 3-<6, \geq 6-<12$, and $\geq 12-<18$ years [18]. The 26 -week treatment period was preceded by a 2 -week screening period and then a 12 -week run-in period where participants discontinued their previous treatment regimens and were switched to trial interventions [18]. Follow-up was on day 7 and day 30 after the end of treatment [18].

The onset 7 trial was conducted in accordance with the Declaration of Helsinki and International Conference on Harmonization of Good Clinical Practice [18]. The trial was approved according to local regulations by the appropriate health authorities and institutional review boards [18]. Informed consent and child assent, as age-appropriate, was obtained before any trial-related activities [18].

\section{Trial population}

Eligible participants were those aged between 1 and 18 years with T1D, hemoglobin A1c $\leq 9.5 \%(80 \mathrm{mmol} / \mathrm{mol})$, and receiving basal-bolus insulin (basal analogue or neutral protamine Hagedorn insulin) for at least 90 days prior to the screening period [18]. During the trial, participants were asked to refrain from using real-time continuous glucose monitoring (CGM) [18].

\section{Trial interventions}

During the run-in period, participants discontinued their previous basal insulin regimen and were switched to insulin degludec (100 units $/ \mathrm{mL}$, once daily) with dose optimization based on protocol-specified guidelines [18]. The basal insulin dose was titrated weekly by the investigator to a pre-breakfast target of 71-145 mg/dL (4.0$8.0 \mathrm{mmol} / \mathrm{L}$ ) [18]. Additional basal insulin dose adjustments were at the investigator's discretion [18].

Participants discontinued their previous bolus insulin regimen during the run-in period, and were switched to IAsp (with a calculated basal:bolus ratio of between 50:50 and 30:70). Bolus insulin dose adjustments were at the investigator's discretion [18]. After the run-in period, eligible participants were randomized 1:1:1 to receive double-blind mealtime faster aspart, double-blind mealtime IAsp, or open-label post-meal faster aspart [18].

Faster aspart or IAsp (100 units $/ \mathrm{mL})$ were administered either 0-2 min before (mealtime dose) or $20 \mathrm{~min}$ after (post-meal dose) starting each of the three main meals [18]. Additional bolus insulin dosing was at the investigator's discretion [18].

During the treatment period, bolus insulin was titrated to a pre-prandial blood glucose (BG) target of 71$145 \mathrm{mg} / \mathrm{dL}(4.0-8.0 \mathrm{mmol} / \mathrm{L})$ and a bedtime target of $120-180 \mathrm{mg} / \mathrm{dL}(6.7-10 \mathrm{mmol} / \mathrm{L})$ in a treat-to-target approach [18]. Bolus dose titration followed flexible 
dosing principles based on carbohydrate counting (which took place several times per day, according to insulin:carbohydrate ratios and a BG correction factor) or via a pre-defined algorithm (on a weekly basis using the lowest pre-meal and bedtime self-measured blood glucose (SMBG) value from the 3 days prior to a site visit/ contact) [18].

\section{SMBG}

Participants were provided with a BG meter (Abbott Precision Neo or Precision; Abbott Laboratories, Chicago, USA), which had been factory-calibrated to display plasma-equivalent values (reported here) [18] Participants were instructed to record the time, date, and value of any SMBG measurements [18]. SMBG measurements taken were 4-point profiles (recorded daily before each main meal and bedtime) and 8-point profiles (recorded on 2 consecutive days prior to visits at weeks 0 , 12, and 26) [18]. Patients were also required to measure their BG levels at the onset of any suspected hypoglycemic episodes and every 15 minutes until SMBG levels were $>3.9 \mathrm{mmol} / \mathrm{L}$ or symptoms had resolved [18].

\section{Endpoints}

The primary endpoint of onset 7 was change in hemoglobin A1c from baseline to week 26. Key supportive secondary endpoints (previously described [18]) included change from baseline to week 26 in PPG and PPG increment (8-point SMBG profile), mean of the 8-point SMBG profile, fasting plasma glucose (FPG), insulin dose, and 1,5-anhydroglucitol (1,5-AG), treatmentemergent adverse events (TEAEs), treatment-emergent hypoglycemic episodes, and change in body weight [18].

\section{Statistical methods}

Efficacy and safety data were summarized using the full analysis set (FAS) and safety analysis set (SAS), respectively, unless otherwise stated [18]. With the exception of insulin dose (on-treatment observation period only), efficacy endpoints were assessed during both the in-trial and on-treatment observation periods [18]. For endpoints stratified by age, data for the $>1-<3$ and $\geq 3-<6$ year age groups were merged before the database was locked, due to the relatively small cohort aged less than 3 years [18].

In the present post-hoc analysis of participants from 34 sites in Japan, statistical analyses were not performed due to small number of participants from Japan. Descriptive statistics based on the last available measurement are presented to summarize measurements at week 26 for efficacy endpoints and body weight.

\section{Results}

\section{Trial participants}

Of the onset 7 trial population $(N=777), 66$ participants from Japan (65 Asian and one non-Asian) were randomized to mealtime faster aspart $(n=24)$, post-meal faster aspart $(n=19)$, or IAsp $(n=23)$, and all were exposed to trial medication. Sixty-four participants (97.0\%) completed the trial and 63 participants $(95.5 \%)$ completed the 26-week treatment period without premature discontinuation of randomized treatment (23 participants [95.8\%] for mealtime faster aspart, 18 participants [94.7\%] for post-meal faster aspart, and 22 participants [95.7\%] for IAsp) (Supplementary Fig. 1). A single participant from each treatment arm discontinued randomized treatment prematurely. Demographic and clinical characteristics at baseline were similar across the three treatment arms (Table 1). The percentage of patients using carbohydrate counting to manage their meals was numerically lower in the mealtime faster aspart group than in the other two groups.

\section{Efficacy}

Mean hemoglobin A1c during the run-in and treatment periods are shown in Fig. 1. Mean hemoglobin A1c increased from baseline to week 26 in each treatment arm, from $7.47 \%$ to $7.70 \%$ for mealtime faster aspart, $7.59 \%$ to $8.44 \%$ for post-meal faster aspart, and $7.52 \%$ to $7.95 \%$ for IAsp. Change from baseline in hemoglobin A1c 26 weeks after randomization was $0.23 \%, 0.74 \%$, and $0.39 \%$, respectively.

More participants in the mealtime faster aspart arm (41.7\%) achieved hemoglobin A1c $<7.5 \%$ by the end of the trial compared with post-meal faster aspart $(5.3 \%)$ or IAsp (26.1\%).

\section{$S M B G$}

The 8-point SMBG profiles at baseline and week 26 are shown in Fig. 2. Increases in mean SMBG from baseline to week 26 were $9.54 \mathrm{mg} / \mathrm{dL}(0.53 \mathrm{mmol} / \mathrm{L})$ for mealtime faster aspart and $14.92 \mathrm{mg} / \mathrm{dL}(0.83 \mathrm{mmol} / \mathrm{L})$ for post-meal faster aspart versus a reduction in mean SMBG for the IAsp arm $(-6.38 \mathrm{mg} / \mathrm{dL},-0.35 \mathrm{mmol} / \mathrm{L})$ (Supplementary Table 1).

Change from baseline in 1-h PPG increment after 26 weeks showed numerical differences in favor of mealtime faster aspart compared with IAsp at breakfast $(-30.70$ vs. $-2.88 \mathrm{mg} / \mathrm{dL} ;-1.70$ vs. $-0.16 \mathrm{mmol} / \mathrm{L})$ and over all meals $(-18.21 \mathrm{vs} .-5.55 \mathrm{mg} / \mathrm{dL} ;-1.01 \mathrm{vs}$. $-0.31 \mathrm{mmol} / \mathrm{L}$ ), and in favor of IAsp compared with post-meal faster aspart at all individual meals (Supplementary Table 1). Change from baseline in 1-h PPG showed a numerical difference in favor of mealtime 
Table 1 Baseline characteristics

\begin{tabular}{lccc}
\hline & $\begin{array}{c}\text { Faster aspart } \\
(\text { mealtime }) \\
n=24\end{array}$ & $\begin{array}{c}\text { Faster aspart } \\
\text { (post-meal) } \\
n=19\end{array}$ & $\begin{array}{c}\text { IAsp } \\
\text { (mealtime) } \\
n=23\end{array}$ \\
\hline Sex, male, $n(\%)$ & $13(54.2)$ & $9(47.4)$ & $16(69.6)$ \\
\hline Age, $n(\%)$ & 0 & $2(10.5)$ & 0 \\
$1-<6$ years & $11(45.8)$ & $7(36.8)$ & $11(47.8)$ \\
$\geq 6-<12$ years & $13(54.2)$ & $10(52.6)$ & $12(52.2)$ \\
$\geq 12-<18$ years & $19.19(2.49)$ & $19.74(3.50)$ & $19.20(2.87)$ \\
\hline BMI, kg/m ${ }^{2}$ & $4.87(4.08)$ & $4.57(2.96)$ & $5.20(2.76)$ \\
\hline Diabetes duration, years & $7.47(0.77)$ & $7.59(0.70)$ & $7.52(0.67)$ \\
\hline Hemoglobin A1c, $\%$ & $58.16(8.37)$ & $59.45(7.70)$ & $58.71(7.33)$ \\
mmol/mol & $125.53(56.05)$ & $154.11(89.26)$ & $156.81(56.44)$ \\
\hline FPG, mg/dL & $6.97(3.11)$ & $8.55(4.95)$ & $8.70(3.13)$ \\
\hline mmol/L & $4(16.7)$ & $5(26.3)$ & $7(30.4)$ \\
\hline Carbohydrate counting, $n(\%)^{a}$ & & & \\
\hline
\end{tabular}

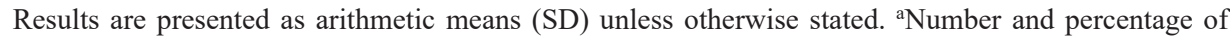
patients using carbohydrate counting.

BMI, body mass index; faster aspart, fast-acting insulin aspart; FPG, fasting plasma glucose; IAsp, insulin aspart; $n$, number of participants; $\mathrm{SD}$, standard deviation.

faster aspart compared with IAsp at both breakfast and lunchtime (Supplementary Table 1).

No clinically significant differences in FPG were reported between the three treatment arms Change from baseline to week 26 in mean FPG was $-5.25 \mathrm{mg} / \mathrm{dL}$ $(-0.29 \mathrm{mmol} / \mathrm{L})$ for mealtime faster aspart, $8.65 \mathrm{mg} / \mathrm{dL}$ $(0.48 \mathrm{mmol} / \mathrm{L})$ for post-meal faster aspart, and -45.30 $\mathrm{mg} / \mathrm{dL}(-2.51 \mathrm{mmol} / \mathrm{L})$ for IAsp (Supplementary Table 1). There was large variation in the FPG data due to difficulties reported by participants in using the home sampling kit.

Mean change from baseline in 1,5-AG after 26 weeks was $-1.02 \mu \mathrm{g} / \mathrm{mL}$ for mealtime faster aspart, -1.83 $\mu \mathrm{g} / \mathrm{mL}$ for post-meal faster aspart, and $-0.52 \mu \mathrm{g} / \mathrm{mL}$ for IAsp (Supplementary Table 1).

\section{Safety}

Hypoglycemia rates are presented in Table 2; $87.5 \%$ of participants in the mealtime faster aspart arm, $89.5 \%$ of participants in the post-meal faster aspart arm, and $100 \%$ of participants in the IAsp arm experienced episodes of severe or BG-confirmed hypoglycemia. The overall rate of severe or BG-confirmed hypoglycemia was numerically lower for mealtime faster aspart (24.29 per patient-year of exposure [PYE]), and numerically higher for post-meal faster aspart (49.10 per PYE) than for IAsp (36.84 per PYE). Throughout the 26-week trial period, episodes of severe or BG-confirmed hypoglycemic accumulated at a constant rate across treatment arms.

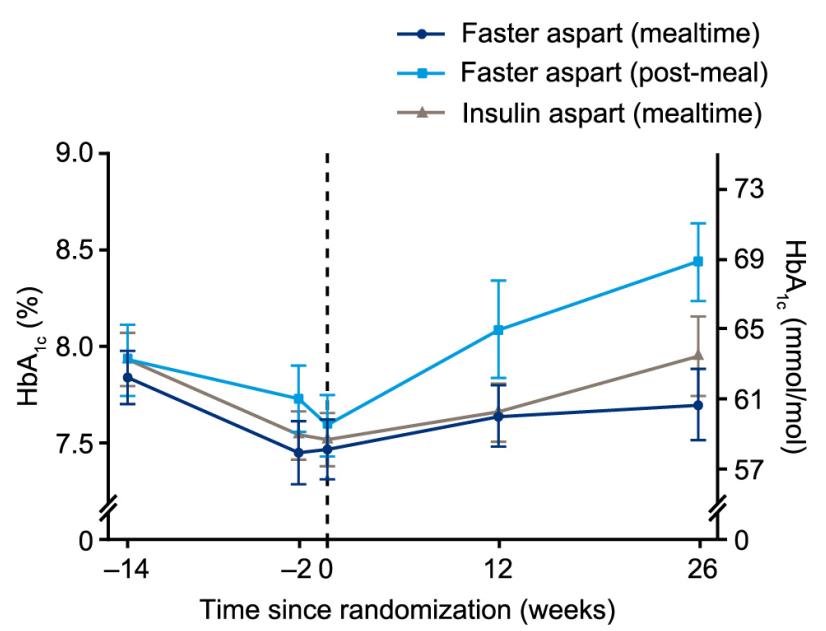

Fig. 1 Mean hemoglobin A1c over time.

During the run-in period, mean hemoglobin A1c decreased from $7.84 \%$ to $7.47 \%$ for participants subsequently randomized to mealtime faster aspart; from $7.93 \%$ to $7.59 \%$ for post-meal faster aspart; and from $7.93 \%$ to $7.52 \%$ for mealtime insulin aspart. After the treatment period, mean hemoglobin A1c was $7.70 \%$, $8.44 \%$, and $7.95 \%$ in the mealtime faster aspart, postmeal faster aspart, and mealtime insulin aspart arms, respectively.

Error bars: \pm standard error. All data presented regardless of treatment discontinuation.

Faster aspart, fast-acting insulin aspart; IAsp, insulin aspart. 

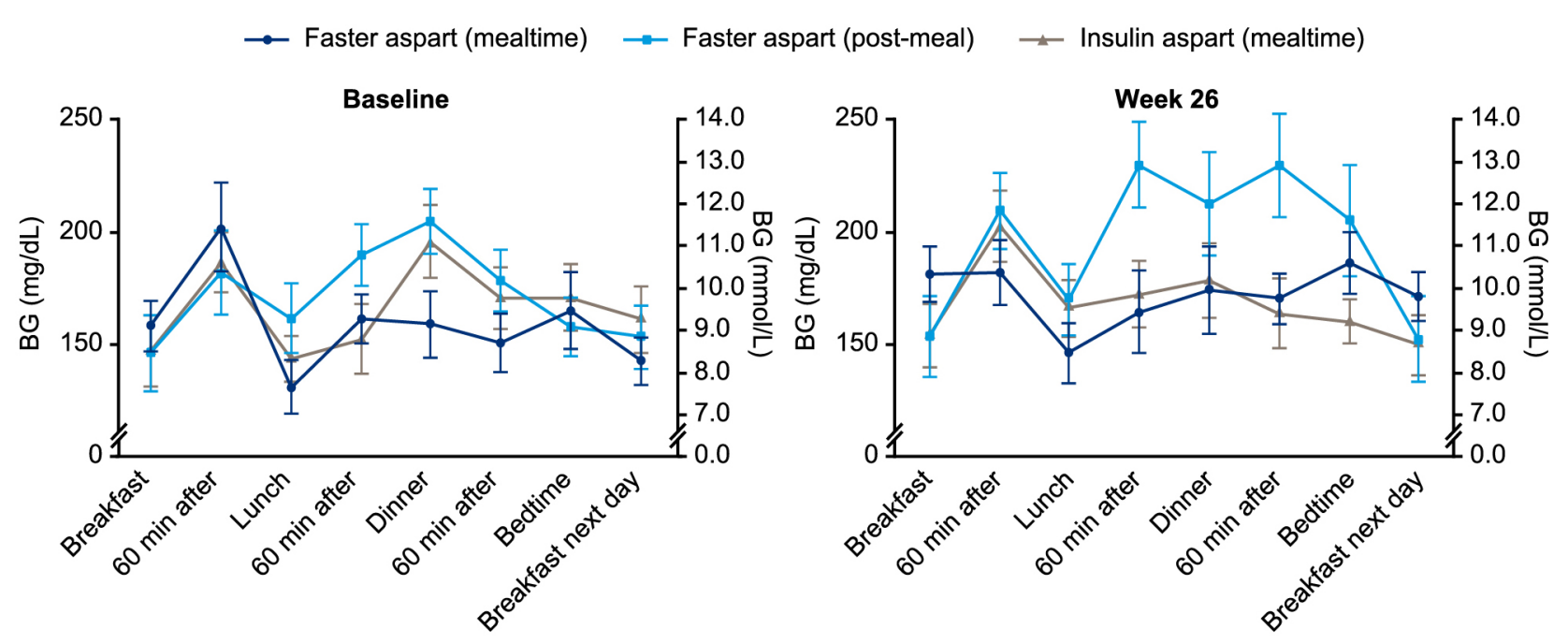

Fig. 2 8-point SMBG profiles at baseline and 26 weeks after randomization.

Error bars: \pm standard error. SMBG profiles are plasma-equivalent values.

BG, blood glucose; faster aspart, fast-acting insulin aspart; IAsp, insulin aspart; SMBG, self-measured blood glucose.

Table 2 Severe or BG-confirmed hypoglycemic episodes

\begin{tabular}{|c|c|c|c|c|c|c|c|c|c|c|c|c|}
\hline & \multicolumn{4}{|c|}{ Faster aspart (mealtime) $n=24$} & \multicolumn{4}{|c|}{ Faster aspart (post-meal) $n=19$} & \multicolumn{4}{|c|}{ IAsp (mealtime) $n=23$} \\
\hline & $N$ & $\%$ & $\mathrm{E}$ & $\mathrm{R}$ & $N$ & $\%$ & $\mathrm{E}$ & $\mathrm{R}$ & $N$ & $\%$ & $\mathrm{E}$ & $\mathrm{R}$ \\
\hline Severe (ISPAD 2014) & 0 & & & & 2 & 10.5 & 2 & 0.22 & 1 & 4.3 & 1 & 0.09 \\
\hline Severe or BG-confirmed & 21 & 87.5 & 284 & 24.29 & 17 & 89.5 & 446 & 49.10 & 23 & 100 & 413 & 36.84 \\
\hline \multicolumn{13}{|c|}{ Meal-related severe or BG-confirmed } \\
\hline Within 1-h after a meal & 2 & 8.3 & 5 & 0.43 & 1 & 5.3 & 1 & 0.11 & 2 & 8.7 & 3 & 0.27 \\
\hline Within 2-h after a meal & 10 & 41.7 & 24 & 2.05 & 9 & 47.4 & 19 & 2.09 & 13 & 56.5 & 34 & 3.03 \\
\hline Within 4-h after a meal & 16 & 66.7 & 70 & 5.99 & 16 & 84.2 & 126 & 13.87 & 18 & 78.3 & 105 & 9.37 \\
\hline
\end{tabular}

Severe or BG-confirmed is defined as severe according to the ISPAD 2014 classification and/or with BG $<56 \mathrm{mg} / \mathrm{dL}(3.1 \mathrm{mmol} / \mathrm{L})$.

$\%$, percentage of participants; BG, blood glucose; E, number of events; faster aspart, fast-acting insulin aspart; IAsp, insulin aspart; ISPAD, International Society for Pediatric and Adolescent Diabetes; $n$, number of participants; $\mathrm{R}$, rate of events per patient year of exposure.

Episodes of severe or BG-confirmed hypoglycemia increased at a higher rate with post-meal faster aspart than with IAsp (i.e. higher number of episodes per participant at all timepoints after 6 weeks post-randomization), and at a lower rate for mealtime faster aspart than with IAsp (Supplementary Fig. 2). Over 24 hours, the highest incidence of severe or BG-confirmed hypoglycemia in all treatment arms occurred at midday (Supplementary Fig. 3).

The incidence of meal-related severe or BG-confirmed hypoglycemia for each treatment arm was similar within 1 hour and 2 hours after a meal (Table 2). Within 4 hours after a meal, the incidence of severe or BG-confirmed hypoglycemia was numerically lower for mealtime faster aspart than for IAsp (5.99 per PYE [66.7\%] vs. 9.37 per PYE [78.3\%]). There were no participants with events that met the ISPAD-defined criteria for severe hypoglycemia in the mealtime faster aspart arm, 2 (10.5\%) participants in the post-meal faster aspart arm, and $1(4.3 \%)$ participant in the IAsp arm (Table 2).

Increases in body weight were observed across all treatment arms. Change from baseline in body weight 26 weeks after randomization was $+2.25 \mathrm{~kg}$ with mealtime faster aspart, $+1.73 \mathrm{~kg}$ with post-meal faster aspart, and $+1.58 \mathrm{~kg}$ with IAsp.

Mean daily bolus and total insulin doses increased over the trial and this was similar across treatment arms (Supplementary Table 2). Mean total insulin dose at week 26 was $1.119 \mathrm{U} / \mathrm{kg} /$ day for mealtime faster aspart, $1.049 \mathrm{U} / \mathrm{kg} /$ day for post-meal faster aspart, and $1.037 \mathrm{U} / \mathrm{kg} /$ day for IAsp.

The distribution of insulin dose at week 26 revealed that all participants had total insulin doses $\geq 0.5 \mathrm{U} / \mathrm{kg} /$ day, and $12.5 \%, 15.8 \%$, and $8.7 \%$ of participants in the mealtime faster aspart, post-meal faster aspart, and IAsp treatment arms, respectively, required an insulin dose $>1.5 \mathrm{U} / \mathrm{kg} /$ day. There was no change in the basal/bolus 
Table 3 Treatment-emergent adverse events

\begin{tabular}{|c|c|c|c|c|c|c|c|c|c|c|c|c|}
\hline & \multicolumn{4}{|c|}{ Faster aspart (mealtime) $n=24$} & \multicolumn{4}{|c|}{ Faster aspart (post-meal) $n=19$} & \multicolumn{4}{|c|}{ IAsp (mealtime) $n=23$} \\
\hline & $N$ & $\%$ & $\mathrm{E}$ & $\mathrm{R}$ & $N$ & $\%$ & $\mathrm{E}$ & $\mathrm{R}$ & $N$ & $\%$ & $\mathrm{E}$ & $\mathrm{R}$ \\
\hline Total events & 19 & 79.2 & 57 & 4.876 & 16 & 84.2 & 50 & 5.504 & 21 & 91.3 & 63 & 5.619 \\
\hline \multicolumn{13}{|l|}{ Severity } \\
\hline Severe & 0 & 0 & 0 & 0 & 1 & 5.3 & 1 & 0.110 & 1 & 4.3 & 1 & 0.089 \\
\hline Moderate & 3 & 12.5 & 6 & 0.513 & 5 & 26.3 & 7 & 0.771 & 4 & 17.4 & 5 & 0.446 \\
\hline Mild & 19 & 79.2 & 51 & 4.362 & 14 & 73.7 & 42 & 4.623 & 20 & 87.0 & 57 & 5.084 \\
\hline
\end{tabular}

A TEAE was defined as an event that has onset up to 7 days after last day of randomized treatment and excluding the events in the run-in period.

$\%$, percentage of participants; E, number of events; faster aspart, fast-acting insulin aspart; IAsp, insulin aspart; $n$, number of participants; $\mathrm{R}$, rate of events per patient year of exposure; TEAE, treatment-emergent adverse event.

split of total daily insulin 26 weeks after randomization in the IAsp treatment arm. A small increase in the percentage of bolus insulin was observed at week 26 in the mealtime and post-meal faster aspart treatment arms. (Supplementary Table 2).

Incidence of TEAEs was similar across treatment arms (mealtime faster aspart 79.2\%; post-meal faster aspart 84.2\%; IAsp 91.3\%; Table 3), and most were considered mild in severity. There were also no clinically relevant differences across treatment arms in other measurements including vital signs, BMI, body weight, height, Tanner staging, antibody measurements, injection site-reactions, laboratory biochemistry, hematology, lipids, or urinalysis.

\section{Discussion}

The onset 7 trial demonstrated that mealtime faster aspart was non-inferior to IAsp in terms of change in hemoglobin Alc 26 weeks after randomization in children and adolescents with T1D [18]. Furthermore, mealtime faster aspart was demonstrated to be superior to IAsp, and post-meal faster aspart non-inferior to IAsp [18]. Post-hoc analysis of participants in Japan, reported here, showed no noteworthy differences between this subgroup and the onset 7 trial population with regard to hemoglobin A1c outcomes between mealtime or postmeal faster aspart and IAsp. Some variation was observed in the subgroup from Japan as would be expected in a smaller subset. The demographic and baseline diabetes characteristics were similar between the subgroup from Japan and the overall trial population. In the subgroup from Japan, fewer patients in the mealtime faster aspart group used carbohydrate counting to manage their meals, but this did not appear to adversely affect glycemic control, which was similar to the other two groups at baseline.

As also noted in the overall trial population, there was a numerical improvement in 1-h PPG increment (aver- aged over all meals based on 8-point SMBG profiles) with mealtime faster aspart compared with IAsp in the subgroup from Japan [18]. Changes in 1-h PPG increments were generally in favor of IAsp compared with post-meal faster. CGM outcomes were not captured in the cohort from Japan, but improvements in mealtimerelated interstitial glucose (IG) increments were observed with mealtime faster aspart versus IAsp in a subgroup of participants using blinded CGM in the overall population [18], while IG increments tended to be in favor of mealtime IAsp versus post-meal faster aspart.

The incidence of severe or BG-confirmed hypoglycemia rates with mealtime faster aspart in the population from Japan was similar to that observed in the overall trial population; however, the incidence with post-meal faster aspart and IAsp was numerically higher in the population from Japan. Within 4 hours after a meal, the incidence of severe or BG-confirmed hypoglycemia was numerically lower for mealtime faster aspart than for IAsp in the population from Japan. While there were no significant differences in meal-related hypoglycemia in the onset 7 population, differences with faster aspart versus IAsp have been reported previously in adult populations and are likely to be attributable to the faster onset and offset of action of faster aspart [17, 19]. It should be noted that caution is needed when interpreting the results from the analysis of the subgroup from Japan given the small sample size. In the observational Japanese Study Group of Insulin Therapy for Childhood and Adolescent Diabetes (JSGIT), mean (standard deviation) rates of severe hypoglycemia were between 8.7 (59.6) and 19.1 (161.8) events per 100 patient-years among cohorts of Japanese pediatric patients with T1D [20]. Self-reported non-severe hypoglycemia was common among Japanese adults with T1D using mealtime insulin in a crosssectional survey, with $26.9 \%$ of patients experiencing more than three events in the last month and $31.7 \%$ experiencing 1-3 events in the last three months [21]. 
While in the same cross-sectional survey, $47.3 \%$ of Japanese patients with T1D reported that they had experienced at least one symptom of post-prandial hyperglycemia (such as fatigue, increased thirst, frequent urination, or blurry vision) a few hours after a meal in the past week [21].

Higher doses of bolus insulin were administered across all three treatment arms in the subgroup from Japan compared with the overall trial population, while basal doses were similar. The higher bolus doses may be due to the high-carbohydrate, low-fat Asian diet [22].

The strengths and limitations of the onset 7 trial have been summarized previously, and largely apply to the subgroup analysis presented here [18]. Strengths of the trial include a large sample size, high retention rate, double-blind trial design, inclusion of a 12-week run-in period, and the use of several glycemic measures to study efficacy [18]. As noted previously, one limitation is the use of a home sampling kit for FPG measurement, which participants found challenging to use and may have been associated with variation in the data [18]. Another potential limitation is that meal composition was not specified during the trial; it was assumed that patients would have received general dietary advice from their own practitioners and, as such, the current trial better reflects real-world clinical practice. The main limitation of the analysis of the subgroup from Japan was the small sample size, which precluded statistical analysis between the treatment groups. Although the findings presented here are only suggestive given the lack of statistical analyses, prescribers in Japan may consider these results together with the results from the overall cohort to inform decisions regarding participant care in this population.

\section{Conclusion}

In accordance with previous findings in the overall onset 7 population of children and adolescents with T1D, analysis of participants from Japan showed that mealtime faster aspart may improve glycemic control compared with IAsp. Importantly, these improvements with mealtime faster aspart were observed with a comparable safety profile to that observed with IAsp.

\section{Acknowledgements}

The authors would like to thank all of the trial participants, staff and investigators. The trial, including study design, data collection, analysis, and interpretation, was funded by Novo Nordisk A/S. Medical writing and editorial assistance were provided by Watermeadow Medical, an Ashfield company, part of UDG Healthcare PLC, funded by Novo Nordisk A/S.

\section{Disclosures}

TKW has received honorarium from Sanofi K.K., Abbvie GK and Eli Lilly Japan K.K. and research funding from Novo Nordisk, Eli Lilly Japan K.K. and Termo K.K. TK has received honorarium from Sanofi K.K. HH, NR, ME are employees of Novo Nordisk. ME also holds stocks/shares in Novo Nordisk. 
Supplementary Table 1 Summary of supportive endpoints (change from baseline in mean SMBG, PPG, incremental PPG, 1,5-AG, and FPG)

\begin{tabular}{|c|c|c|c|}
\hline & $\begin{array}{c}\text { Faster aspart (mealtime), } \\
\% \text { of participants }\end{array}$ & $\begin{array}{c}\text { Faster aspart (post-meal), } \\
\% \text { of participants }\end{array}$ & $\begin{array}{l}\text { IAsp (mealtime), } \\
\% \text { of participants }\end{array}$ \\
\hline \multicolumn{4}{|c|}{ Hemoglobin A1c responders 26 weeks after randomization ${ }^{\mathrm{a}}$} \\
\hline Hemoglobin A1c $<7.5 \%(58.5 \mathrm{mmol} / \mathrm{mol})$ & 41.7 & 5.3 & 26.1 \\
\hline \multirow[t]{2}{*}{$\begin{array}{l}\text { Hemoglobin A1c }<7.5 \%(58.5 \mathrm{mmol} / \mathrm{mol}) \\
\text { without severe hypoglycemia }\end{array}$} & 41.7 & 5.3 & 21.7 \\
\hline & $\begin{array}{c}\text { Faster aspart (mealtime), } \\
\text { mean }\end{array}$ & $\begin{array}{l}\text { Faster aspart (post-meal), } \\
\text { mean }\end{array}$ & $\begin{array}{l}\text { IAsp (mealtime), } \\
\text { mean }\end{array}$ \\
\hline \multicolumn{4}{|c|}{ Change from baseline 26 weeks after randomization ${ }^{\mathrm{b}}$} \\
\hline $\begin{array}{l}\text { Mean 8-point SMBG, } \\
\mathrm{mg} / \mathrm{dL} \\
\mathrm{mmol} / \mathrm{L}\end{array}$ & $\begin{array}{l}9.54 \\
0.53\end{array}$ & $\begin{array}{r}14.92 \\
0.83\end{array}$ & $\begin{array}{l}-6.38 \\
-0.35\end{array}$ \\
\hline $\begin{array}{l}\text { 1-h PPG (SMBG, breakfast), } \\
\text { mg/dL } \\
\text { mmol/L }\end{array}$ & $\begin{array}{r}-22.55 \\
-1.25\end{array}$ & $\begin{array}{r}25.53 \\
1.42\end{array}$ & $\begin{array}{l}5.17 \\
0.29\end{array}$ \\
\hline $\begin{array}{l}\text { 1-h PPG (SMBG, lunch), } \\
\mathrm{mg} / \mathrm{dL} \\
\mathrm{mmol} / \mathrm{L}\end{array}$ & $\begin{array}{l}-3.08 \\
-0.17\end{array}$ & $\begin{array}{r}33.06 \\
1.83\end{array}$ & $\begin{array}{r}14.26 \\
0.79\end{array}$ \\
\hline $\begin{array}{l}\text { 1-h PPG (SMBG, main evening meal), } \\
\mathrm{mg} / \mathrm{dL} \\
\mathrm{mmol} / \mathrm{L}\end{array}$ & $\begin{array}{r}17.10 \\
0.95\end{array}$ & $\begin{array}{r}45.35 \\
2.52\end{array}$ & $\begin{array}{l}-2.95 \\
-0.16\end{array}$ \\
\hline $\begin{array}{l}\text { 1-h PPG (SMBG, all meals), } \\
\text { mg/dL } \\
\text { mmol/L }\end{array}$ & $\begin{array}{r}-10.09 \\
-0.56\end{array}$ & $\begin{array}{r}32.52 \\
1.80\end{array}$ & $\begin{array}{l}5.63 \\
0.31\end{array}$ \\
\hline $\begin{array}{l}\text { 1-h PPG increment (SMBG, breakfast), } \\
\mathrm{mg} / \mathrm{dL} \\
\mathrm{mmol} / \mathrm{L}\end{array}$ & $\begin{array}{r}-30.70 \\
-1.70\end{array}$ & $\begin{array}{r}17.65 \\
0.98\end{array}$ & $\begin{array}{l}-2.88 \\
-0.16\end{array}$ \\
\hline $\begin{array}{l}\text { 1-h PPG increment (SMBG, lunch), } \\
\mathrm{mg} / \mathrm{dL} \\
\mathrm{mmol} / \mathrm{L}\end{array}$ & $\begin{array}{r}-13.42 \\
-0.74\end{array}$ & $\begin{array}{r}22.38 \\
1.24\end{array}$ & $\begin{array}{r}-18.53 \\
-1.03\end{array}$ \\
\hline $\begin{array}{l}\text { 1-h PPG increment (SMBG, main evening } \\
\mathrm{mg} / \mathrm{dL} \\
\mathrm{mmol} / \mathrm{L}\end{array}$ & $\begin{array}{r}15.83 \\
0.88\end{array}$ & $\begin{array}{r}58.91 \\
3.27\end{array}$ & $\begin{array}{l}1.24 \\
0.07\end{array}$ \\
\hline $\begin{array}{l}\text { 1-h PPG increment (SMBG, all meals), } \\
\mathrm{mg} / \mathrm{dL} \\
\mathrm{mmol} / \mathrm{L}\end{array}$ & $\begin{array}{r}-18.21 \\
-1.01\end{array}$ & $\begin{array}{r}27.54 \\
1.53\end{array}$ & $\begin{array}{l}-5.55 \\
-0.31\end{array}$ \\
\hline $1,5-\mathrm{AG}, \mu \mathrm{g} / \mathrm{mL}$ & -1.02 & -1.83 & -0.52 \\
\hline $\begin{array}{l}\text { FPG, } \\
\qquad \mathrm{mg} / \mathrm{dL} \\
\mathrm{mmol} / \mathrm{L}\end{array}$ & $\begin{array}{l}-5.25 \\
-0.29\end{array}$ & $\begin{array}{l}8.65 \\
0.48\end{array}$ & $\begin{array}{r}-45.30 \\
-2.51\end{array}$ \\
\hline
\end{tabular}

a Subjects without hemoglobin A1c at week 26 were treated as non-responders.

${ }^{\mathrm{b}}$ Week 26 contains last available measurement.

All available information regardless of treatment discontinuation was used. SMBG measurements are plasma-equivalent glucose values.

1,5-AG, 1,5-anhydroglucitol; faster aspart, fast-acting insulin aspart; FPG, fasting plasma glucose; IAsp, insulin aspart; PPG, post-prandial glucose; SMBG, self-measured blood glucose. 
Supplementary Table 2 (a) Daily bolus, basal, and total insulin dose (actual) and (b) basal/bolus ratios of total daily insulin

(a)

\begin{tabular}{|c|c|c|c|c|c|c|c|}
\hline \multirow{2}{*}{ Visit (week) } & \multirow{2}{*}{ Treatment } & \multicolumn{6}{|c|}{ Insulin dose } \\
\hline & & $N^{*}$ & Mean & SD & Median & Min & Max \\
\hline \multicolumn{8}{|c|}{ Bolus dose (all meals), $U$} \\
\hline \multirow{3}{*}{ Week 0} & Faster aspart (mealtime) & 24 & 26.4 & 13.5 & 24.7 & 5 & 54 \\
\hline & Faster aspart (post-meal) & 19 & 26.7 & 15.5 & 26.0 & 8 & 55 \\
\hline & IAsp (mealtime) & 23 & 26.5 & 13.3 & 24.7 & 6 & 51 \\
\hline \multirow{3}{*}{ Week $26^{\mathrm{a}}$} & Faster aspart (mealtime) & 24 & 34.8 & 19.6 & 34.3 & 6 & 84 \\
\hline & Faster aspart (post-meal) & 19 & 32.5 & 21.4 & 31.0 & 8 & 78 \\
\hline & IAsp (mealtime) & 23 & 29.6 & 15.3 & 24.3 & 9 & 69 \\
\hline \multicolumn{8}{|l|}{ Basal dose, $U$} \\
\hline \multirow{3}{*}{ Week 0} & Faster aspart (mealtime) & 24 & 17.1 & 6.8 & 16.0 & 6 & 29 \\
\hline & Faster aspart (post-meal) & 19 & 15.2 & 8.8 & 12.3 & 2 & 35 \\
\hline & IAsp (mealtime) & 23 & 17.6 & 9.7 & 14.0 & 7 & 44 \\
\hline \multirow{3}{*}{ Week $26^{\mathrm{a}}$} & Faster aspart (mealtime) & 24 & 18.1 & 7.2 & 16.5 & 7 & 33 \\
\hline & Faster aspart (post-meal) & 19 & 16.4 & 10.2 & 15.0 & 2 & 42 \\
\hline & IAsp (mealtime) & 23 & 18.9 & 9.6 & 16.0 & 8 & 42 \\
\hline \multicolumn{8}{|c|}{ Total insulin dose, $\mathrm{U}$} \\
\hline \multirow{3}{*}{ Week 0} & Faster aspart (mealtime) & 24 & 43.5 & 18.3 & 45.8 & 12 & 70 \\
\hline & Faster aspart (post-meal) & 19 & 41.9 & 22.7 & 39.3 & 12 & 77 \\
\hline & IAsp (mealtime) & 23 & 44.1 & 20.9 & 37.0 & 15 & 90 \\
\hline \multirow{3}{*}{ Week $26^{\mathrm{a}}$} & Faster aspart (mealtime) & 24 & 52.9 & 24.5 & 49.3 & 13 & 100 \\
\hline & Faster aspart (post-meal) & 19 & 48.9 & 29.9 & 46.5 & 13 & 120 \\
\hline & IAsp (mealtime) & 23 & 48.5 & 21.9 & 49.0 & 19 & 99 \\
\hline \multicolumn{8}{|c|}{ Bolus dose (all meals), U/kg } \\
\hline \multirow{3}{*}{ Week 0} & Faster aspart (mealtime) & 24 & 0.575 & 0.214 & 0.577 & 0.22 & 1.05 \\
\hline & Faster aspart (post-meal) & 19 & 0.612 & 0.203 & 0.587 & 0.35 & 1.06 \\
\hline & IAsp (mealtime) & 23 & 0.575 & 0.189 & 0.545 & 0.22 & 1.01 \\
\hline \multirow{3}{*}{ Week $26^{\mathrm{a}}$} & Faster aspart (mealtime) & 24 & 0.728 & 0.367 & 0.654 & 0.30 & 2.00 \\
\hline & Faster aspart (post-meal) & 19 & 0.696 & 0.300 & 0.640 & 0.35 & 1.49 \\
\hline & IAsp (mealtime) & 23 & 0.631 & 0.289 & 0.579 & 0.36 & 1.74 \\
\hline \multicolumn{8}{|c|}{ Basal dose, $\mathrm{U} / \mathrm{kg}$} \\
\hline \multirow{3}{*}{ Week 0} & Faster aspart (mealtime) & 24 & 0.391 & 0.111 & 0.365 & 0.21 & 0.68 \\
\hline & Faster aspart (post-meal) & 19 & 0.341 & 0.119 & 0.328 & 0.16 & 0.52 \\
\hline & IAsp (mealtime) & 23 & 0.388 & 0.143 & 0.357 & 0.18 & 0.73 \\
\hline \multirow{3}{*}{ Week $26^{\mathrm{a}}$} & Faster aspart (mealtime) & 24 & 0.391 & 0.102 & 0.368 & 0.21 & 0.58 \\
\hline & Faster aspart (post-meal) & 18 & 0.357 & 0.130 & 0.348 & 0.15 & 0.60 \\
\hline & IAsp (mealtime) & 22 & 0.412 & 0.149 & 0.400 & 0.23 & 0.75 \\
\hline \multicolumn{8}{|c|}{ Total insulin dose, $\mathrm{U} / \mathrm{kg}$} \\
\hline \multirow{3}{*}{ Week 0} & Faster aspart (mealtime) & 24 & 0.966 & 0.257 & 0.917 & 0.61 & 1.67 \\
\hline & Faster aspart (post-meal) & 19 & 0.954 & 0.236 & 0.983 & 0.53 & 1.35 \\
\hline & IAsp (mealtime) & 23 & 0.963 & 0.271 & 0.931 & 0.58 & 1.50 \\
\hline \multirow{3}{*}{ Week $26^{\mathrm{a}}$} & Faster aspart (mealtime) & 24 & 1.119 & 0.404 & 1.003 & 0.64 & 2.38 \\
\hline & Faster aspart (post-meal) & 19 & 1.049 & 0.353 & 0.987 & 0.56 & 1.75 \\
\hline & IAsp (mealtime) & 23 & 1.037 & 0.374 & 0.994 & 0.64 & 2.50 \\
\hline
\end{tabular}

${ }^{a}$ Week 26 contains last available measurement.

\begin{tabular}{lccc}
\hline (b) & & & \\
\hline Basal/bolus ratio & Faster aspart (mealtime) & Faster aspart (post-meal) & IAsp (mealtime) \\
\hline Week 0 & $41 / 59$ & $36 / 64$ & $40 / 60$ \\
Week 26 & $35 / 65$ & $34 / 66$ & $40 / 60$
\end{tabular}

Safety analysis set.

Faster aspart, fast-acting insulin aspart; IAsp, insulin aspart; $N$, number of participants; SD, standard deviation. 


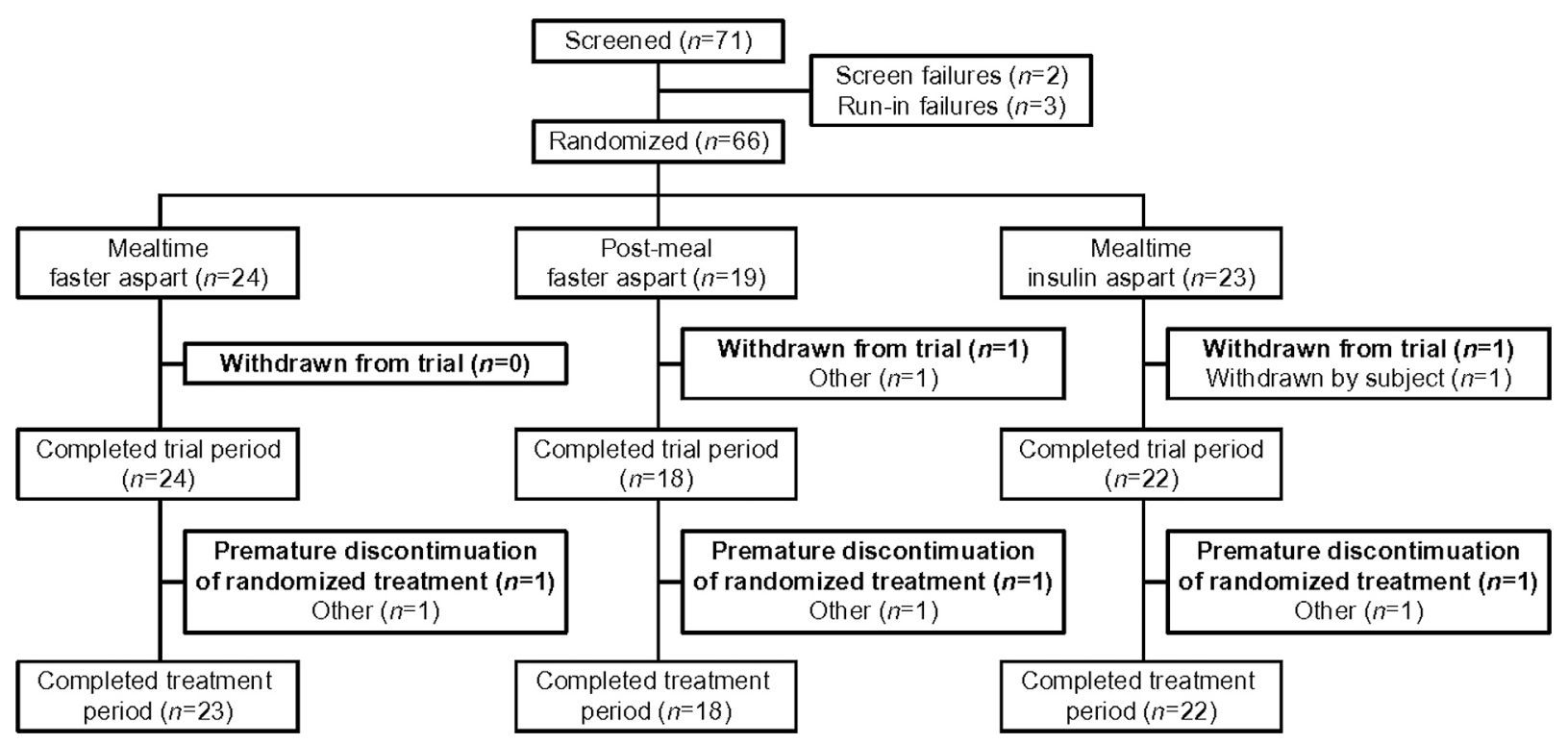

Supplementary Fig. 1 Participant disposition.

Treatment period: the period from week 0 to week 26 without premature discontinuation of randomized treatment. Trial period: the period from week 0 to week 30 .

Faster aspart, fast-acting insulin aspart; $n$, number of participants.

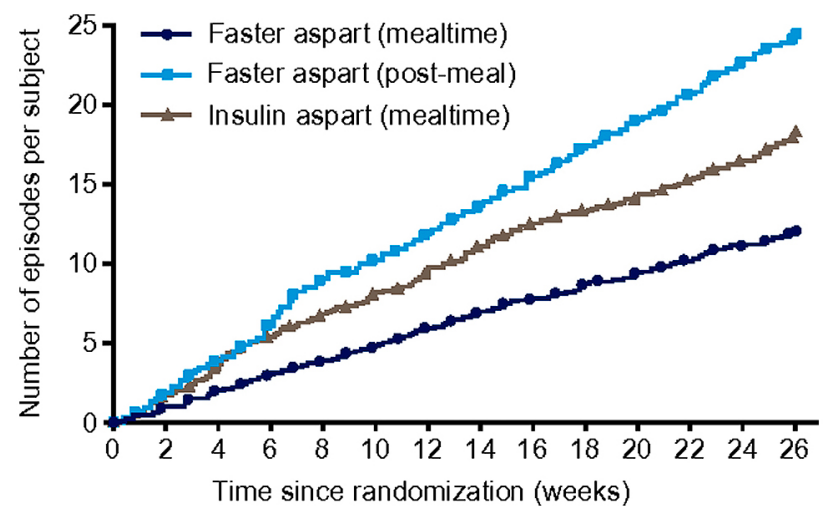

Supplementary Fig. 2 Cumulative incidence of severe or blood glucose-confirmed hypoglycemia

Mean cumulative function of treatment-emergent severe or BG-confirmed hypoglycemic episodes (on-treatment). Events are treatment-emergent, defined as having onset up to 1 day after last day of randomized treatment and excluding events in the run-in period. Severe or BG-confirmed, severe according to the ISPAD 2014 classification and/or with $\mathrm{BG}<56 \mathrm{mg} / \mathrm{dL}(3.1 \mathrm{mmol} / \mathrm{L})$. Throughout the 26 weeks of the treatment period, the rates of severe or BG-confirmed hypoglycemic episodes accumulated at a constant rate in each of the treatment groups. The rate for mealtime faster aspart increased at a lower rate than IAsp, while the rate for post-meal faster aspart increased at a higher rate than IAsp.

$\mathrm{BG}$, blood glucose; faster aspart, fast-acting insulin aspart; IAsp, insulin aspart; ISPAD, International Society for Pediatric and Adolescent Diabetes. 


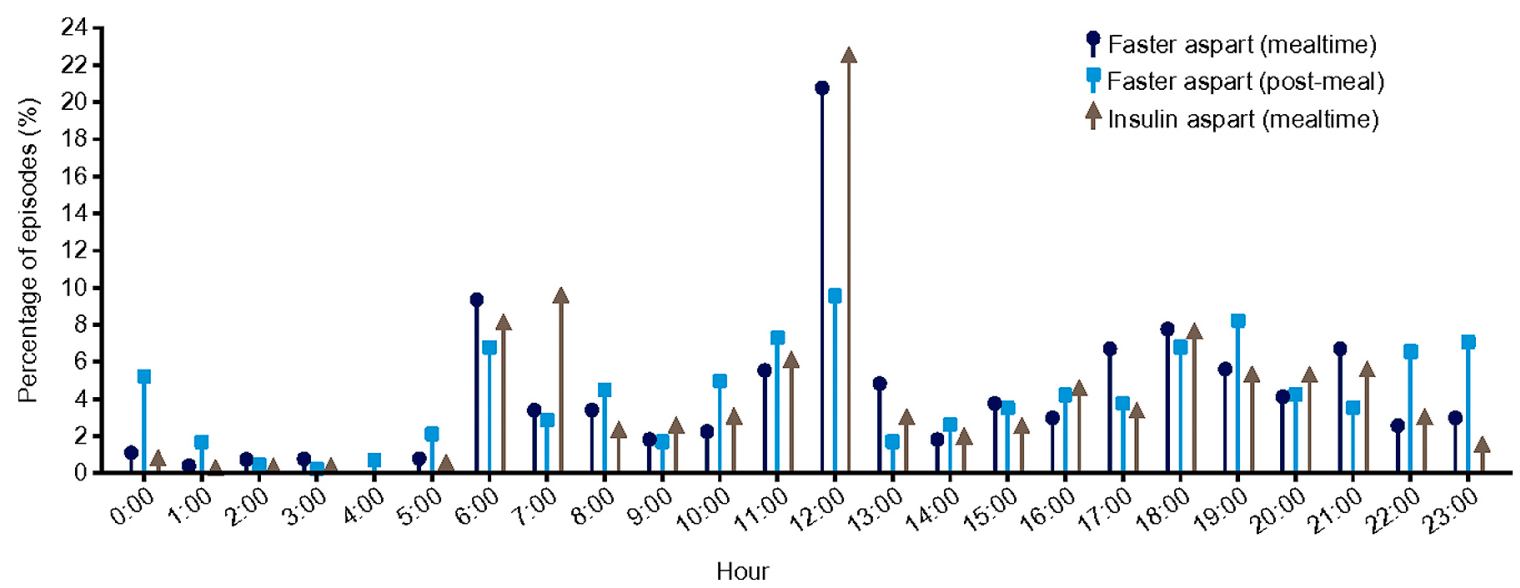

Supplementary Fig. 3 Distribution of episodes of severe or BG-confirmed hypoglycemia over 24 hours.

Distribution of episodes of treatment-emergent severe or BG-confirmed hypoglycemic episodes over 24 hours (on-treatment). Events are treatment-emergent, defined as having onset up to 1 day after last day of randomized treatment and excluding events in the run-in period. Severe or BG-confirmed, severe according to the ISPAD 2014 classification and/or with $\mathrm{BG}<56 \mathrm{mg} / \mathrm{dL}(3.1 \mathrm{mmol} / \mathrm{L})$.

BG, blood glucose; faster aspart, fast-acting insulin aspart; IAsp, insulin aspart; ISPAD, International Society for Pediatric and Adolescent Diabetes.

\section{References}

1. Onda Y, Sugihara S, Ogata T, Yokoya S, Yokoyama T, et al. (2017) Incidence and prevalence of childhood-onset type 1 diabetes in Japan: the T1D study. Diabet Med 34: 909-915.

2. Xia Y, Xie Z, Huang G, Zhou Z (2019) Incidence and trend of type 1 diabetes and the underlying environmental determinants. Diabetes Metab Res Rev 35: e3075.

3. Ikegami H, Noso S, Babaya N, Hiromine Y, Kawabata Y (2008) Genetic basis of type 1 diabetes: similarities and differences between east and west. Rev Diabet Stud 5: 6472.

4. Danne T, Phillip M, Buckingham BA, Jarosz-Chobot P, Saboo B, et al. (2018) ISPAD Clinical Practice Consensus Guidelines 2018: insulin treatment in children and adolescents with diabetes. Pediatr Diabetes 19 Suppl 27: 115135.

5. Chiang JL, Maahs DM, Garvey KC, Hood KK, Laffel LM, et al. (2018) Type 1 diabetes in children and adolescents: a position statement by the American Diabetes Association. Diabetes Care 41: 2026-2044.

6. Haneda M, Noda M, Origasa H, Noto H, Yabe D, et al. (2018) Japanese Clinical Practice Guideline for Diabetes 2016. J Diabetes Investig 9: 657-697.

7. Biester T, Kordonouri O, Danne T (2018) Pharmacotherapy of type1 diabetes in children and adolescents: more than insulin? Ther Adv Endocrinol Metab 9: 157-166.

8. DiMeglio LA, Acerini CL, Codner E, Craig ME, Hofer SE, et al. (2018) ISPAD Clinical Practice Consensus Guidelines 2018: glycemic control targets and glucose monitoring for children, adolescents, and young adults with diabetes. Pediatr Diabetes 19 Suppl 27: 105-114.

9. Araki E, Haneda M, Kasuga M, Nishikawa T, Kondo T, et al. (2017) New glycemic targets for patients with diabetes from the Japan Diabetes Society. J Diabetes Investig 8: 123-125.

10. Cengiz E (2012) Undeniable need for ultrafast-acting insulin: the pediatric perspective. J Diabetes Sci Technol 6: 797-801.

11. Woerle HJ, Neumann C, Zschau S, Tenner S, Irsigler A, et al. (2007) Impact of fasting and postprandial glycemia on overall glycemic control in type 2 diabetes Importance of postprandial glycemia to achieve target HbAlc levels. Diabetes Res Clin Pract 77: 280-285.

12. Shimizu H, Uehara Y, Okada S, Mori M (2008) Contribution of fasting and postprandial hyperglycemia to hemoglobin A1c in insulin-treated Japanese diabetic patients. Endocr J 55: 753-756.

13. Herring R, Russell-Jones DDL (2018) Lessons for modern insulin development. Diabet Med 35: 1320-1328.

14. Kildegaard J, Buckley ST, Nielsen RH, Povlsen GK, Seested T, et al. (2019) Elucidating the mechanism of absorption of fast-acting insulin aspart: the role of niacinamide. Pharm Res 36: 49.

15. Shiramoto M, Nishida T, Hansen AK, Haahr H (2018) Fast-acting insulin aspart in Japanese patients with type 1 diabetes: faster onset, higher early exposure and greater early glucose-lowering effect relative to insulin aspart. $J$ Diabetes Investig 9: 303-310.

16. Fath M, Danne T, Biester T, Erichsen L, Kordonouri O, et al. (2017) Faster-acting insulin aspart provides faster onset 
and greater early exposure $v$ s. insulin aspart in children and adolescents with type 1 diabetes mellitus. Pediatr Diabetes 18: 903-910.

17. Heise T, Pieber TR, Danne T, Erichsen L, Haahr H (2017) A pooled analysis of clinical pharmacology trials investigating the pharmacokinetic and pharmacodynamic characteristics of fast-acting insulin aspart in adults with type 1 diabetes. Clin Pharmacokinet 56: 551-559.

18. Bode BW, Iotova V, Kovarenko M, Laffel LM, Rao PV, et al. (2019) Efficacy and safety of fast-acting insulin aspart compared with insulin aspart, both in combination with insulin degludec, in children and adolescents with type 1 diabetes: the onset 7 trial. Diabetes Care 42: 1255 1262.

19. Buse JB, Carlson AL, Komatsu M, Mosenzon O, Rose L, et al. (2018) Fast-acting insulin aspart versus insulin aspart in the setting of insulin degludec-treated type 1 dia- betes: efficacy and safety from a randomized double-blind trial. Diabetes Obes Metab 20: 2885-2893.

20. Mochizuki M, Kikuchi T, Urakami T, Kikuchi N, Kawamura T, et al. (2017) Improvement in glycemic control through changes in insulin regimens: findings from a Japanese cohort of children and adolescents with type 1 diabetes. Pediatr Diabetes 18: 435-442.

21. Ishii H, Shuichi S, Williams P, Demiya S, Aranishi T, et al. (2020) Cross-sectional survey in patients with type 1 and type 2 diabetes to understand mealtime insulin unmet needs in Japan: the MINUTES-J study. Diabetes Res Clin Pract 162: 108076.

22. Hashimoto T, Kawamura T, Kashihara Y, Hirose M, Higashide T, et al. (2012) Factors associated with basal insulin dose in Japanese children and young adult type 1 diabetics. J Diabetes Investig 3: 276-282. 